\title{
Epidemiological Study and Causative Agent Identification of Contagious Bovine Pleuropneumonia in Selected Districts of Western Ethiopia
}

\author{
Tesfaye Mersha Cherinnat \\ Oromia Agricultural Research Institute, Bako Agricultural Research Center, Ethiopia
}

*Corresponding Author: Tesfaye Mersha Cherinnat, Oromia Agricultural Research Institute, Bako Agricultural Research Center, Ethiopia

\begin{abstract}
Contagious bovine pleuropneumonia (CBPP) is a highly contagious disease of cattle caused by Mycoplasma mycoides subsp. mycoides small colony (Mmm SC). A cross-sectional study design was conducted to estimate seroprevalence and associated risk factors and to detect the causative agent of the disease from seropositive animals. Therefore, a total of 576 animals were randomly selected and serum samples were collected and tested with c-ELISA. For further confirmation from 4 seropositive animals lung tissue were sampled and detection of antigen was made using PCR.Thus, the overall animal and herd level seroprevalence of CBPP were 14.6\% (95\%CI: 11.80-17.73) and 54\% (95\% CI: 44.35-63.40), respectively. Among the potential risk factors considered, multivariate logistic regression analysis showed district, age, herd size, and history of respiratory disorder were statistically significant(p <0.05). Cattle that found in Ilu Galan district were two times $(O R=2.4, P=0.002)$ more likely to be affected by the disease than Sibu Sire, adult cattle were two times $(O R=2.1, p=0.009)$ more likely positive than young, large herd cattle were six times $(O R=6.1, P=0.000)$ more likely affected than small herd, and animals that had history of respiratory problems were two times $(O R=1.9, P=0.021)$ more likely seropositive than healthy. Of 4 seropositive animals lung tissue tested with PCR, Mmm SC was detected in all samples (100\%). In conclusion like molecular method in non-vaccinated areas serological technique can also correctly estimate the presence of the disease. Therefore, the government has to prioritize the control and prevention strategy of this economically devastating disease of cattle particularly the implementation of regular vaccination of young animal is significant in disease endemic areas.
\end{abstract}

Keywords: CBPP; Seroprevalence; Risk factors; c-ELISA; PCR; Mmm SC; Western Ethiopia

\section{INTRODUCTION}

Contagious bovine pleuropneumonia (CBPP) is a contagious disease of cattle caused by Mycoplasma mycoides subsp. mycoides small colony ( $\mathrm{Mmm} \mathrm{SC)}$. It has great potential for rapid spread and causes major impact on cattle production. The disease is manifested by anorexia, fever and respiratory signs such as dyspnoea, polypnoea, cough and nasal discharges $(1,2)$. The principal route of infection is inhalation of infective droplets derived from diseased animals. Outbreaks tend to be more extensive in housed and in those in transit by train and on foot (3). Factors such as extremes of age, stress and concurrent infections may predispose to tissue invasion (4). It is considered to be a disease of economic importance because of its mortality, production loss, increased production cost due to cost of disease control, loss of weight and working ability, reduced fertility, and restricted cattle trade (3, 5). Due to its high economic impact, the World Organisation for Animal Health (OIE) declared CBPP as one of the most serious contagious animal diseases and listed on the group of notifiable animal diseases of high socio-economic impact and regarded as major transboundary animal diseases (TADs) (6).

Thus, CBPP is one of the great plagues that continue to devastate the cattle herds on which so many people are dependent in Africa and considered as the most infectious animal disease affecting cattle of the continent $(7,8)$. The disease spread alarmingly during the $1990 \mathrm{~s}$, infecting several countries previously free from the disease and causing greater losses $(9,10)$. In recent years, the disease has emerged from areas where it has been persisting in endemic form to re-invade other areas from which it had previously been eradicated (6). In addition to these newly infected areas, the endemic areas are experiencing an upsurge in the incidence of CBPP (6). 
With the imminent eradication of rinderpest, CBPP has becoming the most important cattle disease that hinders livestock development of Ethiopia. This is mainly caused due to the interruption of the consecutive yearly blanket vaccinations with combined rinderpest. Since 1992-1993 which had certainly contained the disease to a relatively low level during the past years by reducing the susceptible bovine population. However, CBPP is now re-emerging as one of the most economically important diseases that impede livestock production. Poor understanding of pathogenesis, relatively ineffective vaccines with adverse effects and poor diagnostic assays were further exacerbated the impact of the disease in the country (11). Ethiopia has experienced the largest number of cattle deaths, and reduction in cattle products under both endemic and epidemic conditions of CBPP compared to other African countries probably due to large cattle population (12). Therefore, CBPP was considered as one of the most important cattle disease and impediments to livestock development in Ethiopia $(13,14)$.

In most continents, control strategies are based on the early detection of outbreaks, control of animal movements and stamping-out policy. However, in Africa control of the disease is only based on vaccination (T1/44 or T1SR) and antibiotic treatment $(3,15)$. However, the consequences of antibiotic treatments in terms of clinical efficacy, emergence of resistant strains and persistence of chronic carriers have not been evaluated yet (16). But currently research work has shown that antibiotic treatment of cattle may greatly reduce the transmission to healthy contacts but this requires treatment of all affected cattle (17). Despite vaccination has been considered as a strategy for the control of CBPP in Ethiopia, the disease still persists in several regions of the country and its incidence increasing from year to year. This is, mainly due to lack of effective vaccine, irregular and low coverage of vaccination, lack of livestock movement control, and absence of systematic disease surveillance and reliable data (11).

Knowing the extent of diseases distribution like CBPP is valuable since used as an input for development of optimum prevention and controlling strategies and that will ultimately assist in poverty alleviation by improving the productivity of the sector. Therefore, to carry out an effective control of the disease, prerequisites such as understanding of the epidemiological scenario of the disease should be well-known. However, currently there were several studies have been undertaken since 2006 on CBPP as a country with prevalence of $0.4 \% 31.8 \%(18,19,20,21,22,23,24)$. The previous studies were stressed only on seroprevalence study, whereas there is no reported document on detection of the causative agent of the disease using PCR technique in the country so far. Hence, further identification of the causative agent of CBPP and knowing the epidemiological scenario of the disease is vital. Therefore, the study was conducted with the objectives of estimating seroprevalence and associated risk factors of CBPP and detecting the causative agent of the disease from seropositive animals.

\section{MATERIALS AND METHODS}

\subsection{Description of the Study Area}

The study was carried out in selected districts (Sibu-Sire and Ilu-Galan) which were selected from two zones (East Wollega and West Showa) of Oromia regional state, western Ethiopia.

Sibu Sire district is found western part of Ethiopia in East Wollega zone of Oromiya regional state (Fig. 1). The district is located on the Addis Ababa-Nekemte main road about $273 \mathrm{~km}$ from the Ethiopian capital Addis Ababa to the west of the country. Sire is the central town of the district and is located on geographical coordinates $9^{\circ} 04^{\prime} 59.9^{\prime \prime} \mathrm{N}$ and $36^{\circ} 49^{\prime} 59.9^{\prime \prime} \mathrm{E}$. The district has altitude ranging from 1,200-2,400 with an average of 1,830 meters above sea level (m.a.s.l). The agro ecologies of the area are $7.53 \%$ highland, $74.2 \%$ midland and $18.7 \%$ lowland type. It experiences a bimodal pattern of rainfall with the main rainy season extending from June to September (84\% of rain is expected) and short rainy seasons from March to May. The area receives rainfall ranging from 1,000-2,400 $\mathrm{mm}$ with mean annual rainfall of $1,700 \mathrm{~mm}$. The minimum and maximum temperatures of the district were $10.9^{\circ} \mathrm{C}$ and $33.9^{\circ} \mathrm{C}$, respectively. The livestock populations of the district were: cattle $(190,166)$, sheep $(35,952)$, goat $(36,512)$, poultry $(193155)$, horse $(12,249)$, donkey $(16,402)$ and mules $(1,196)$. According to the document of Sibu Sire veterinary clinic described the major livestock diseases that found in the district were trypanomosis, internal and external parasite, lumpy skin viral disease, pasturellosis, mastitis, blackleg, Newcastle viral disease anthrax and tuberculosis (25 Sibu Sire district Livestock and Fishery Resource Development Office, 2017). 
Ilu-Gelan district is found in the western part of Ethiopia in West Showa zone of Oromiya regional state (Fig. 1). The district is located on the Addis Ababa-Nekemte main road about $200 \mathrm{~km}$ from Addis Ababa to the west of the country. Ijaji is the central town of the district and the district is located on geographical coordinates $8^{\circ} 59^{\prime} 51^{\prime \prime} \mathrm{N}$ and $37^{\circ} 19^{\prime} 49^{\prime \prime} \mathrm{E}$. The altitude of the district is ranging from 1,5651,790 with an average of 1, 630 m.a.s.l. The agro-ecology of the area is almost about $80 \%$ is lowland type. The mean annual rainfall of the area varies between 1,600-2,290 mm and the mean annual temperature is $27.3 \%$. The current livestock populations of the district based on species are 107,076 cattle, 7,600 sheep, 8,930 goats, 41,285 poultry, 650 horses, 950 mules, and 3,395 donkeys. According to the report of Ilu Galan livestock health agency, the major endemic livestock diseases that found in the district were trypanomosis, pasturellosis, blackleg, salmonellosis, epizootic lymphagitis, African horse sickness, mengimites, and external parasite (ticks) (26 Ilu Gelan district Livestock and Fishery Resource Development Office, 2017).

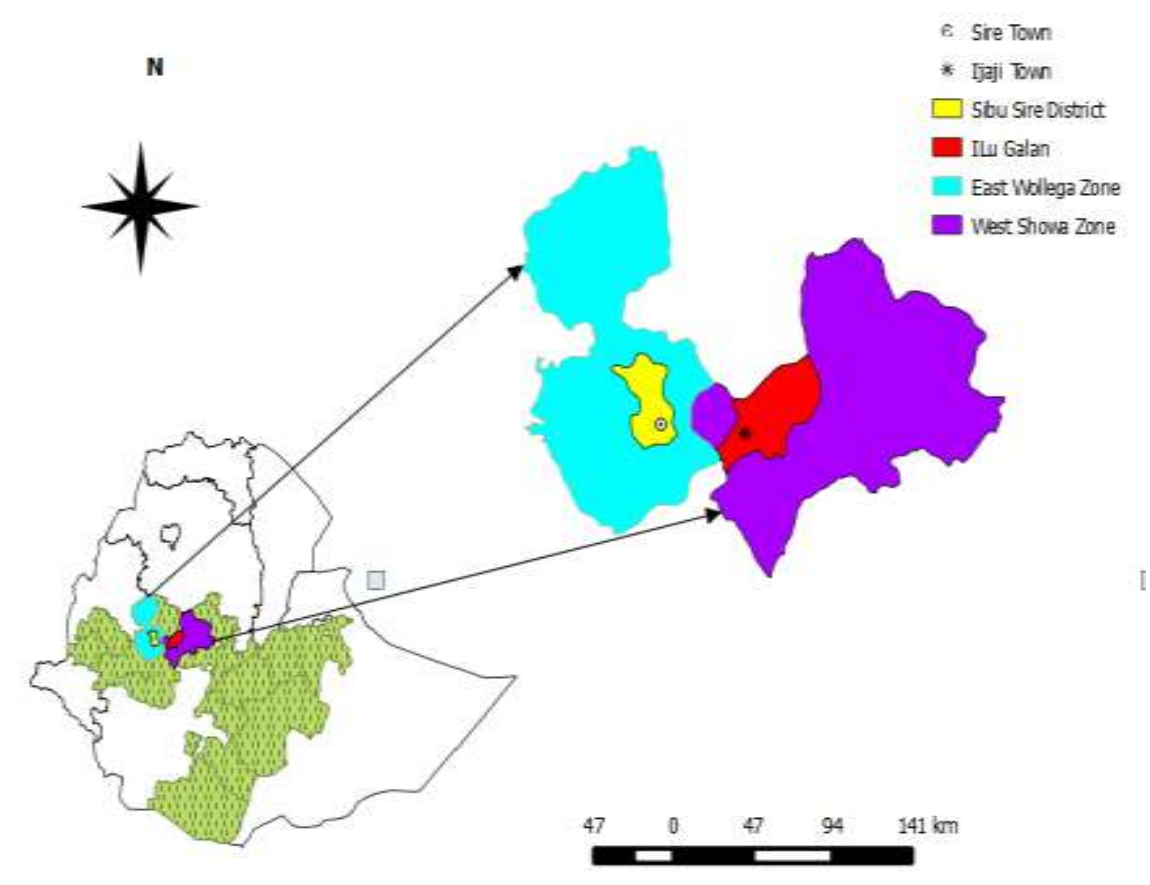

Fig1. Map of the study area

\subsection{Study Population}

The study population comprises indigenous Horro cattle breeds that found in the areas. Horro breed is zenga type cattle that are an intermediate breed type between the sanga and the zebu. Zenga breeds are often found in areas between the typical zebu areas in northern Africa and Sanga areas in the south (25, 26, and 27). The Horro cattle are found in the western parts of Ethiopia, mainly in the Eastern Wollega and Western Shoa zones of the Oromia region and one of the common breed in Ethiopia. Therefore, indigenous Horro cattle breed that managed under extensive production system with no history of CBPP vaccination and animals above six months old age were subjects of the study. Most of the time calves are not included in serological studies since it was believed that the colostrum milk might be trigger antibodies for many diseases that able to protect up to six months of old age.

\subsection{Study Design and Methods}

The cross-sectional study design was conducted from December 2016 to April 2017 in selected districts (Sibu Sire and Ilu Galan) of western Ethiopia and equal sample size were considered for the two districts. The purpose of the study was fully explained to the selected cattle owners before conducting the study to have owners' agreement. From the selected study areas animals' blood samples collections were performed and the overall animal and herd level seroprevalence of CBPP were estimated. As well as the associated potential risk factors of CBPP were identified. For further confirmation of the presence of CBPP in the study area, identification of the causative agent of CBPP disease was made from lung tissue samples of seropositive animals. 


\subsection{Sampling and Sample Size Determination}

\subsubsection{Sample Size Determination}

The sample size required for venous blood collection was determined depending on the expected overall prevalence of CBPP, $5 \%$ the desired absolute precision and $95 \%$ confidence interval $(\mathrm{CI})$ using the formula given by Thrusfield (28). Since there were recent previous reports of prevalence of CBPP disease in western part of the country such as $28.5 \%$ was reported by Mersha (23) and $6.51 \%$ was reported by Geresu et al. (24) and the average was $17.51 \%$. Thus, in this study an expected prevalence of $17.51 \%$ was considered to get the maximum sample size. Therefore, the sample size was calculated based on $17.51 \%$ expected prevalence and gives total sample size of 216 for each district. However, 288 animals were sampled from each district in order to increase the precision, which gives a total estimated sample size of 576 animals.

The sample size calculation formula:

$\mathrm{n}=\underline{(1.96)^{2}(\mathrm{Pexp})(1-\mathrm{Pexp})}$

$\mathrm{d}^{2}$

Where; $\mathrm{n}=$ Total number of sample size

Pexp $=$ Expected prevalence, $\mathrm{d}=$ Absolute precision (0.05)

\subsubsection{Sampling Techniques}

To select the study districts non-probability sampling (purposive sampling) technique was used. In the first stage the two districts (Sibu Sire from East Wollega zone and Ilu Gelan from West Shoa zone) were selected purposively based on nearby to Bako agricultural research centre, easily accessible and densely populated area of cattle. In the second stage, after made of a brief discussion with the selected districts of livestock and fishery resource development office and health agencies, peasant associations (PAs) which mean the smallest administrative unit of the districts were randomly selected from the two districts. Sibu Sire district has 22 PAs whereas Ilu Galan has 17 PAs, and from each district two PAs were randomly selected. Thus, from Sibu Sire (Lalisa and Cheri Jarso) and from Ilu Galan (Ale Wara Ilu and Wadeyi Granche) were sampled, accordingly.

To select households (herds) and individual animal two stage sampling methods were employed. The primary sampling unit was household that having at least two cattle in each selected PA and defined as herd. To select households or herds, since the total numbers of households that having cattle (sampling frame) in each PA were not well known, purposive sampling technique was used. Therefore, from each PA, households that having at least two cattle were recruited purposively based on households that found nearby to PA level veterinary clinics (type D clinics). And the secondary sampling unit was individual animals of households (animals that owned by the sampled households). Since between-cluster variance of CBPP disease of the area was unknown a simple random sampling method was applied to calculate the number of animals to be included from each herd in study (29). From each list of herds (household that having animal) the maximum sample size sampled was seven (i.e. the average number of cattle per household of the area). From households those having greater than seven cattle, only seven animals were sampled using random sampling method. However, in case of households that have $\leq 7$ cattle, all animals were sampled (30). Households (cattle owners) of the study area were recognises each cattle owned by name, thus, animals were randomly sampled using the name of animal as ID number and blood samples collections were conducted.

\subsection{Data Collection}

\subsubsection{Blood Sample Collection}

Blood samples of animals belonging to interviewed farmers were collected for diagnostic test. Therefore, from each sampled animal about $7 \mathrm{ml}$ of whole blood were collected from the jugular vein of the randomly sampled animals using disposable plain vacutainer tubes and needles (BD Vacutainer Systems, Plymouth, United Kingdom) according to best practice of guidelines. Then, the samples were properly labelled and left for $24 \mathrm{~h}$ at room temperature to allow clotting and serum samples were separated after $24 \mathrm{~h}$ through gently transferring to other sterile vials and stored at $-20^{\circ} \mathrm{C}$ at Bako Agricultural Research Centre animal health laboratory until submitted to National Veterinary Institute 
(NVI), Bishoftu. Finally, the serum samples were transported in to NVI with an ice box and submitted for laboratory analysis.

During blood sample collection variable that considered as risk factors were: location (districts and PAs); age (grouped into two 6 months- 3 years old called young and greater than 3 years old called adult based on owners information); sex (male and female); herd size (grouped into three, since the interviewed minimum and maximum number of herd sizes ranges 2-25 categorised as 2-7 called small herds, 8-14 called medium herds and 15-25 large herds); previous history of respiratory disorder (yes/present or no/absent); body condition score (BCS) characterised based on (31) principles, then categorised into three poor 0-3, medium 4-6 and good 7-9); and parity (categorised as heifer or non parturated, primiparus or single and pluriparus or multiple parity).

\subsubsection{Lung Tissue Sampling}

After CBPP positive animals were screened using serological method, and trace backing of seropositive animal owners made to purchase seropositive animals for lung tissue sampling. Before starting the process of purchasing, the purpose of purchasing animals was clearly explained to the owners in order to have owners' agreement. Out of the total 84 seropositive animals which were resulted test positive using competitive enzyme-linked immunosorbent assay (cELISA), four animals were purposively selected based on strength of seropositivity (bigger percent of inhibition value) and bought. The purchased seropositive animals were transported to Bako Agricultural Research Centre and post-mortem examinations have been conducted. Upon post-mortem examination parts of suspected lesions of lung tissue samples were collected and immediately stored at $-20^{\circ} \mathrm{C}$ at Bako Agricultural Research Centre, animal health laboratory until submitted to NVI, Bishoftu. Finally, the lung tissue samples were dispatched into NVI with an ice box and submitted for PCR analysis.

\subsection{Diagnostic Methods}

\subsubsection{Competitive Enzyme-Linked Immunosorbent Assay}

Microplates are coated with $\mathrm{Mmm}$ purified lysate. Samples to be tested are premixed with a specific monoclonal antibody (MAb) $117 / 5$ in a separate plate (prelate) and content of the prelate is transferred into the coated microplate. Any $\mathrm{Mmm}$ specific antibodies present in the sample will form an immunecomplex with $\mathrm{Mmm}$ antigen coated on the microplate, competing with MAb 117/5 for the specific epitopes. After washing away unbound material, an anti-mouse antibody enzyme conjugate is added. In presence of immune-complex between $\mathrm{Mmm}$ antigen and antibodies from the sample, MAb 117/5 cannot bind to its specific epitopes and the conjugate is blocked from binding to MAb 117/5. Conversely in the absence of Mmm-antibodies in the test sample, MAb 117/5 can bind to its specific epitopes and the conjugate is free to bind to MAb 117/5. Unbound conjugate is washed away, and enzyme substrate called tetramethylbenzidine (TMB) is added. In presence of the enzyme, the substrate is oxidised and develops a blue compound becoming yellow after blocking. Subsequent colour development is inversely proportional to the amount of anti- $\mathrm{Mmm}$ antibodies in the test sample. The result is expressed in "percentage of inhibition" by comparing the optical density in the test well with the optical densities in the MAb control wells (NVI laboratory manual).

\subsubsection{Polymerase Chain Reaction}

The deoxyribonucleic acid (DNA) extraction process from lung tissues samples were carried out as described by (32). The tissue samples were cut in small pieces using a sterile scalpel, grinded thoroughly and then homogenised in $2 \mathrm{ml}$ phosphate buffered saline (PBS). Then, the mixture was transferred to $2 \mathrm{ml}$ Eppendorf tubes containing $385 \mu \mathrm{l}$ sodium chloride-Tris EDTA (STE) buffer $(100 \mathrm{mM} \mathrm{NaCl}, 50 \mathrm{mM}$ Tris-HCl, $\mathrm{pH} 7.4$, and $1 \mathrm{mM}$ EDTA), $5 \mu$ proteinase $\mathrm{K}(20 \mathrm{mg} / \mathrm{ml})$, and $10 \mu \mathrm{l}$ Sodium dodecyl sulfate (SDS) (20\%). After extraction with $400 \mu \mathrm{l}$ phenol saturated with $1 \mathrm{mM}$ Tris$\mathrm{HCl}\left(\mathrm{pH}\right.$ 7.4) and ethanol precipitation, the DNA was dissolved in $50 \mu \mathrm{l}$ of distilled $\mathrm{H}_{2} \mathrm{O}$.

Then DNA amplification was performed using Mycoplasma mycoides subsp. mycoides speciesspecific pair primers and $5 \mu \mathrm{l}$ of test DNA template in a total volume of $20 \mu \mathrm{l}$ for 42 cycles. The reaction mixture consisted of RNase free water (3 $\mu \mathrm{l})$, Primer-MSC1-Fow- $5 \mathrm{pM} / \mu 1$ 5'ATACTTCTGTTCTAGTAATATG-3' $(2 \quad \mu l)$, Primer-MSC2-REV-5pM/ $\mu 1 \quad 5$ '-CT GATTATGATGACAGTGGTTCA-3' $(2 \mu \mathrm{l})$, IQ Super mix $(10 \mu \mathrm{l})$, template (DNA) $(3 \mu \mathrm{l})$. The optimal amplification cycle for paired primers sets consisted of initial denaturation at $95^{\circ} \mathrm{C}$ for $5 \mathrm{~min}$ 
(1-Cycle), a 40 cycles of each denaturation at $95^{\circ} \mathrm{C}$ for $30 \mathrm{sec}$, annealing at $50^{\circ} \mathrm{C}$ for $30 \mathrm{sec}$, and initial elongation at $72^{\circ} \mathrm{C}$ for $1 \mathrm{~min}$, final elongation at $72^{\circ} \mathrm{C}$ for $7 \mathrm{~min}(1-\mathrm{Cycle})$ and the products were kept at $4^{\circ} \mathrm{C}$ for electrophoresis. The positive control $\mathrm{Mmm}$ DNA used while nuclease free water and extraction control samples were used as negative control. To confirm the targeted PCR amplification the PCR product was then subjected to electrophoresis in the $1.5 \%$ agarose gel containing $5 \mu \mathrm{l}$ gel red with $4 \mu \mathrm{l}$ dye and $10 \mu \mathrm{L}$ of DNA Ladder (Gene Ruler, Fermentas, United States of America) was prepared and electrophoresis was carried out at 130 volts for $1 \mathrm{~h}$ and the products were read under ultraviolet illumination adapted to molecular imaging software. The amplified product which produced specific bands with the molecular size of 260 base pair is observed in positive samples by ultraviolet trans-illumination (NVI laboratory manual).

\subsection{Data Management and Analysis}

Data were stored on Microsoft Excel spread sheet ver 2013, and analysis was made using STATA (version 13) and SPSS ver. 20 statistical softwares. Disease prevalence was analyzed using SPSS (descriptive statistical test mean crosstabs) was used while degree of associations between the outcome variable and its potential risk factors were analyzed using STATA (version 13) using logistic regression model. CBPP sero positive was considered as the dependent variable and the risk factors as independent variables. Initially logistic regression of univariable analysis of measuring odds ratio made and the significant results of the univariate analysis were included in the final model using multivariate logistic regression analysis. Finally, the degree of association was computed using odds ratio (OR) signified by $95 \% \mathrm{CI}$ with a p-value less than 0.05 taken as significant.

\section{RESUlTS}

\subsection{Seroprevalence and Associated Risk Factors of Contagious Bovine Pleuropneumonia}

\subsubsection{The Overall Animal and Herd Level Seroprevalence}

Of the total 576 sampled animals from 113 cattle herds, 84 were seropositive with CBPP disease. The overall animal level seroprevalence CBPP was $14.6 \%$ (95\% CI: 11.80-17.73). Out of the total 113 sampled herds, 61 herds were infected and the overall herd level seroprevalence of CBPP was 54\% (95\% CI: 44.35-63.40).

\subsubsection{Animal Level Seroprevalence of Contagious Bovine Pleuropneumonia Across the Risk Factors}

In this study different animal level seroprevalence was recorded across the study locations such as higher prevalence was observed in Ilu Gelan district (20.1\%) than Sibu Sire district (9\%). Similarly, highest prevalence was recorded in Ale Wara Ilu (22.1\%) while lowest in Cheri Jarso (7\%). In the present study also, various prevalence were recorded across host related potential risk factors like sex, age, parity and body condition of the animals. As the result of the study described seropositivity was higher: in adult $(18.1 \%)$ than in young $(9.6 \%)$, highest in poor body condition $(23.3 \%)$ than in medium (12.8\%) and good body condition (6.4\%) and highest seroprevalence in pluriparus (17.1\%) while lowest in heifers (7.6\%) were recorded. As well as highest seroprevalence was observed in large herd size $(30.6 \%)$ than small herd size $(5.5 \%)$ and higher prevalence $(18.8 \%)$ in animals with history respiratory disorder than healthy animals $(10.2 \%)$ (Table I).

Univariate logistic regression analysis results showed that among the risk factors that considered district, age, history of respiratory disorder, herd size and body condition were spastically significant $(p<0.05)$. The animal level seroprevalence was significantly higher in Ilu Galan district than in Sibu Sire such as cattle that found in Ilu Galan (OR $=2.54,95 \%$ CI: $1.55-4.17, p=0.000)$ were more than two times more likely to be affected by CBPP disease than Sibu Sire. Similarly, cattle that kept at Ale Wara Ilu (OR $=2.3,95 \%$ CI: $1.2-4.4, p=0.012)$ were 2.3 times more likely to be CBPP seropositive than Lelisa. The likelihood of seropositivity with CBPP disease of adult cattle (OR $=2.1,95 \% \mathrm{CI}$ : 1.24-3.46, $p=0.005$ ) were two times more seropositive than young, animals which had history of respiratory problems $(\mathrm{OR}=2.04,95 \% \mathrm{CI}: 1.26-3.31, p=0.004)$ were two times more likely to be seropositive than those hadn't, poor body condition animals $(\mathrm{OR}=4.4,95 \% \mathrm{CI}$ : $1.84-10.64$, $p=0.001)$ were four times more likely to be seropositive than good body condition and cattle that found in large herds (OR $=7.6,95 \% \mathrm{CI}$ : 3.84-14.94, $p=0.000)$ were seven times more likely to be affected by CBPP disease than small herds. As well as the likelihood of getting risk of infection with $\mathrm{CBPP}$ disease of multiple parity $(\mathrm{OR}=2.5,95 \% \mathrm{CI}: 1.16-5.51, p=0.020)$ were two times more than heifers (Table I). 
Epidemiological Study and Causative Agent Identification of Contagious Bovine Pleuropneumonia in Selected Districts of Western Ethiopia

Table1. Animal level seroprevalence degree of association analysis across potential risk factors using univariate logistic regression

\begin{tabular}{|c|c|c|c|c|c|}
\hline \multirow{3}{*}{\begin{tabular}{|l|} 
Risk factors \\
District \\
\end{tabular}} & \multirow[t]{3}{*}{ No.tested } & \multirow[t]{3}{*}{$\%(95 \% \mathrm{CI})$} & \multicolumn{2}{|c|}{\begin{tabular}{|c|} 
Report of odds ratios \\
\end{tabular}} & \multirow[t]{3}{*}{$p$-value } \\
\hline & & & OR (95\% CI) & Std.Err. & \\
\hline & & & & & \\
\hline Sibu Sire & 288 & $9(5.98-12.95)$ & 1 & & \\
\hline Ilu Galan & 288 & $20.1(15.66-25.24)$ & $2.54(1.55-4.17)$ & 0.64 & $0.000 * * *$ \\
\hline \multicolumn{6}{|l|}{ PA (Kebele) } \\
\hline Lelisa & 146 & $11(6.4-17.19)$ & 1 & & \\
\hline Cheri Jarso & 142 & $7(3.43-12.57)$ & $0.62(0.27-1.41)$ & 0.26 & 0.250 \\
\hline Ale Wara Ilu & 145 & $22.1(15.61-29.70)$ & $1.8(0.92-3.53)$ & 0.62 & 0.084 \\
\hline Wadeyi Granche & 143 & $18.2(12.23-25.49)$ & $2.3(1.2-4.4)$ & 0.74 & $0.012 *$ \\
\hline \multicolumn{6}{|l|}{ Sex } \\
\hline Female & 326 & $13.2(9.71-17.35)$ & 1 & & \\
\hline Male & 250 & $16.4(12.03-21.58)$ & $1.3(0.81-2.05)$ & 0.31 & 0.280 \\
\hline \multicolumn{6}{|l|}{ Age } \\
\hline Young & 239 & $9.6(6.2-14.1)$ & 1 & & \\
\hline Adult & 337 & $18.1(14.14-22.63)$ & $2.1(1.24-3.46)$ & 0.54 & $0.005 * *$ \\
\hline \multicolumn{6}{|l|}{ Herd size } \\
\hline Small & 228 & $5.5(2.74-9.01)$ & 1 & & \\
\hline Medium & 211 & $12.8(8.2-17.27)$ & $2.5(1.24-5.1)$ & 0.9 & $0.011^{*}$ \\
\hline Large & 147 & $30.6(23.3-38.74)$ & $7.6(3.84-14.94)$ & 2.6 & $0.000 * * *$ \\
\hline \multicolumn{6}{|l|}{ History of RD } \\
\hline No & 284 & $10.2(6.95-14.34)$ & 1 & & \\
\hline Yes & 292 & $18.8(14.52-23.80)$ & $2.04(1.26-3.31)$ & 0.5 & $0.004 * *$ \\
\hline \multicolumn{6}{|l|}{ BCS } \\
\hline Good & 109 & $6.4(2.62-12.78)$ & 1 & & \\
\hline Medium & 351 & $14.2(10.76-18.35)$ & $2.42(1.06-5.51)$ & & $0.035^{*}$ \\
\hline Poor & 116 & $23.3(15.93-32.03)$ & $4.4(1.84-10.64)$ & 1.98 & $0.001 * *$ \\
\hline \multicolumn{6}{|l|}{ Parity } \\
\hline Heifer & 132 & $7.6(3.69-13.49)$ & 1 & & \\
\hline Primiparus & 48 & $16.7(7.48-30.22)$ & $2.44(0.9-6.61)$ & 1.24 & 0.079 \\
\hline Pluriparus & 140 & $17.1(11.30-24.42)$ & $2.5(1.16-5.51)$ & 1 & $0.020 *$ \\
\hline
\end{tabular}

BSC: body condition score, CI: confidence interval, OR: odds ratio, PA: peasant association, RD: respiratory disorder, Std.Err.: standard error. Note: Number of stars describes the degree of significance

*: statistically significant $(*=$ weekly significant, $* *=$ strong significant, $* * *=$ very strong significant)

Table2. The result of multivariate logistic regression potential risk factors of individual animal level seroprevalence degree of association analysis

\begin{tabular}{|l|l|l|l|}
\hline \multirow{2}{*}{ Risk factors } & \multicolumn{2}{|c|}{ Report of odds ratios } & \multicolumn{1}{|l}{ Stvalue } \\
\cline { 2 - 3 } & OR (95\% CI) & & \\
\hline District & & & \\
\hline Sibu Sire & 1 & 0.64 & $0.002^{* *}$ \\
\hline Ilu Galan & $2.4(1.4-4)$ & & \\
\hline Age & & & \\
\hline Young & 1 & 0.58 & $0.009^{* *}$ \\
\hline Adult & $2.1(1.2-3.6)$ & & \\
\hline History of RD & & & $0.021^{*}$ \\
\hline No & 1 & 0.5 & \\
\hline Yes & $1.9(1.1-3)$ & & \\
\hline Herd size & & & $0.016^{*}$ \\
\hline Small & 1 & 0.9 & $0.000^{* * *}$ \\
\hline Medium & $2.4(1.2-5)$ & 2.2 & \\
\hline Large & $6.1(3-12)$ & & \\
\hline
\end{tabular}

CI: confidence interval, OR: odds ratio, RD: respiratory disorder, Std.Err.: standard errorNote: Number of stars describes the degree of significance. *: statistically significant $(*=$ weekly significant, **=strong significant, $* * *=$ very strong significant) 
Epidemiological Study and Causative Agent Identification of Contagious Bovine Pleuropneumonia in Selected Districts of Western Ethiopia

Initially, univariate logistic regression was used to screen all potential risk factors for statistical significance at $(p<0.05)$ and variables that found statistically significant were subjected to multivariate logistic regression analysis with forward and backward variable selection approach based on the likelihood ratio statistic $(p<0.05)$. The risk factors (district, age, and history of respiratory disorder, BCS and herd size) that statistically significant in univariable logistic regression analysis were included in the model and analysed together. Therefore, the final multivariable logistic regression model analysis result showed that district, age, history of respiratory disorder and herd size were statistically significant association with CBPP seroprevalence $(p<0.05)$ (Table II).

\subsection{Herd Level Seroprevalence of Contagious Bovine Pleuropneumonia Across the Associated Risk Factors}

In the present study the risk factors that considered at herd level seroprevalence were district, PA, herd size and history of respiratory health problems within the herd. The herd level CBPP seropositive was higher in Ilu Gelan (67.2\%) than in Sibu Sire (30\%). Among, the four sampled PAs the herd level prevalence was highest in Ale Wara Ilu (71\%) while lowest in Cheri Jarso (30.8\%). Similarly, highest herd level seroprevalence was observed in large herd size (83.9\%) while lowest in small herd size (32.6\%). Regarding to the history of occurrence of respiratory health problem, herds that encountered history of respiratory disorder had greater prevalence (56.9\%) than those hadn't encountered (50.9\%).

Univariate logistic regression analysis results showed that among herd level risk factors (district, PA, herd size and history of respiratory problem and herd size) that considered, only district and herd size were statically significant effect on seropositivity $(p<0.05)$. Such as the likelihood of cattle herds infection with CBPP disease in Ilu Galan district (OR $=3.1,95 \%$ CI: $1.43-6.64, p=0.004)$ three times more than Sibu Sire. The chance of seropositivity with CBPP disease in larger herd (OR $=10.8$, 95\% CI: 3.4-34), $p=0.000$ ) ten times more likely than smaller herds (Table III)

Table3. Univariate logistic regression degree of association analysis of potential risk factors with herd level seroprevalence

\begin{tabular}{|c|c|c|c|c|c|}
\hline \multirow[t]{2}{*}{ Risk factors } & \multirow[t]{2}{*}{ Total herd } & \multirow[t]{2}{*}{$\%(95 \% \mathrm{CI})$} & \multicolumn{2}{|c|}{ Report of odds ratios } & \multirow[t]{2}{*}{$p$-value } \\
\hline & & & OR (95\% CI) & Std. Err. & \\
\hline \multicolumn{6}{|l|}{ District } \\
\hline Sibu Sire & 55 & $30(27.22-54.1)$ & 1 & & \\
\hline Ilu Galan & 58 & $67.2(53.66-78.99)$ & $3.1(1.43-6.64)$ & 1.21 & $0.004 * *$ \\
\hline \multicolumn{6}{|l|}{ PA } \\
\hline Lelisa & 29 & $48.3(29.45-67.47)$ & 1 & & \\
\hline Cheri Jarso & 26 & $30.8(14.33-51.79)$ & $0.48(0.16-1.44)$ & 0.27 & 0.189 \\
\hline Wadeyi Granche & 31 & $71(51.96-85.78)$ & $1.82(0.63-5.3)$ & 0.99 & 0.271 \\
\hline Ale Wara Ilu & 27 & $63(42.37-80.60)$ & $2.62(0.9-7.59)$ & 1.42 & 0.076 \\
\hline \multicolumn{6}{|l|}{ Herd size } \\
\hline Small & 31 & $83.9(66.3-94.5)$ & 1 & & \\
\hline Medium & 39 & $53.8(37.2-69.9)$ & $2.4(0.99-5.9)$ & 1.1 & $0.05^{*}$ \\
\hline Large & 43 & $32.6(19.1-48-.5)$ & $10.8(3.4-34)$ & 6.3 & $0.000 * * *$ \\
\hline \multicolumn{6}{|l|}{ History of RD } \\
\hline No & 55 & $50.9(37.07-64.65)$ & 1 & & \\
\hline Yes & 58 & $56.9(43.23-69.84)$ & $1.27(0.61-2.67)$ & 0.48 & 0.524 \\
\hline
\end{tabular}

CI: confidence interval, OR: odds ratio, PA: peasant association, RD: respiratory disorder, Std.Err.: standard error, Note: Number of stars describes the degree of significance. *: statistically significant $(*=$ weekly significant, $* *=$ strong significant, $* * *=$ very strong significant)

\subsection{Detection of Mycoplasma Mycoides Subsp. Mycoides Using Polymerase Chain Reaction}

Out of the four seropositive animals that post-mortem examination made $2 / 4$ (50\%) had lesions of CBPP infection. Lung tissue was encapsulated and consolidated mean separated by a network of pale bands made thickening extensive fibrosis marbling and formed pleural adhesions, lung organ was strongly attached to chest walls (Fig. 2), and the lung tissue became inflamed (Fig. 3) 


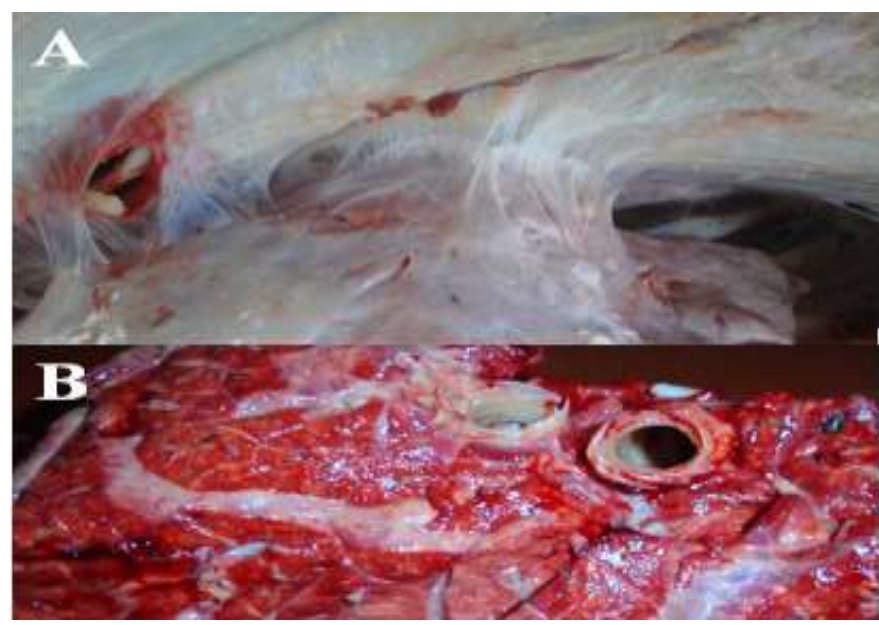

Fig2. (A) Contagious bovine pleuropneumonia seropositive slaughtered cow of lung organ adhesion to the chest wall and $(B)$ Network of pale bands and made thickening extensive fibrin or fibrosis marbling appearance of lung tissue
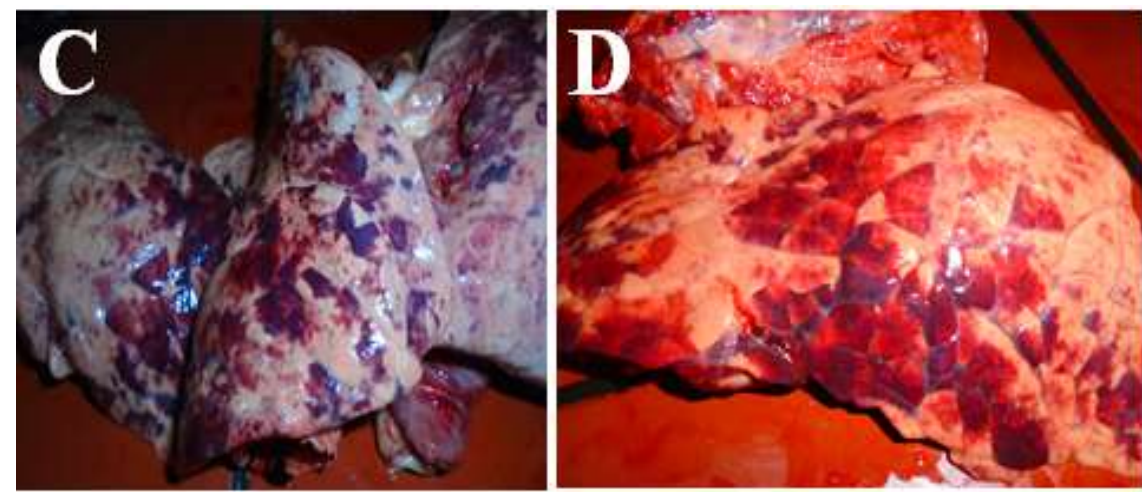

Fig3. ( $C$ and $D)$ The lung of contagious bovine pleuropneumonia seropositive young male bull slaughtered and its lung was severely inflamed upon post-mortem examination as the picture indicates

Upon post-mortem examination while the other two lung samples were had no CBPP lesions.

Of the four seropositive samples that tested with PCR, Mmm SC antigen was detected in all four samples (100\%). Thus, the PCR test result was indicated below as Mmm.SC antigen was detected in all sampled animals lung tissues. The amplified product that produced specific bands with the molecular size of $260 \mathrm{bp}$ was observed on agarose gel electrophoresis which indicated the presence of Mmm DNA in the samples (positive) (Fig. 4).

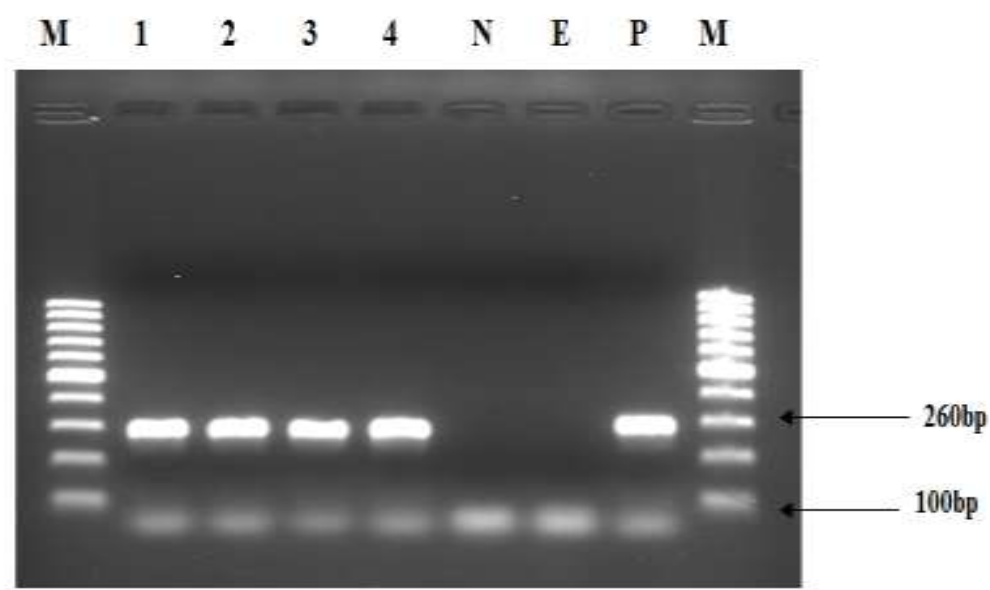

Fig4. Gel electrophoresis of polymerase chain reaction products of samples which yielded bacterial genomic deoxyribonucleic acid, $M$ (lanes 1 and 9): molecular ladder or molecular weight markers started $100 \mathrm{bp}$ (Fermentas) 1Kb, Lanes 1-4: positive field samples extracted DNA, Lane $N$ : RNase free water (negative control), Lane E: extraction control (negative control), Lane P: positive control, DNA: deoxyribonucleic acid 
Epidemiological Study and Causative Agent Identification of Contagious Bovine Pleuropneumonia in Selected Districts of Western Ethiopia

The identification of the causative agent of CBPP using molecular method (PCR) from seropositive animals were summarised on Table IV.

Table4. Summary of postmortem examination and PCR result

\begin{tabular}{|c|c|c|c|c|c|c|}
\hline $\begin{array}{l}\stackrel{0}{z} \\
\dot{0} \\
\underline{\alpha}\end{array}$ & & 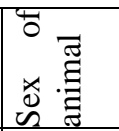 & $\begin{array}{l}\text { Life animal Serum } \\
\text { c-ELISA result }\end{array}$ & $\begin{array}{l}\text { Post mortem observation } \\
\text { result }\end{array}$ & $\begin{array}{l}\text { Type of sample used } \\
\text { for molecular test }\end{array}$ & PCR- result \\
\hline 4 & 3 & Male & ++ & Typical CBPP lesions & Lung tissue & + \\
\hline 3 & 8 & Male & ++ & No CBPP lesions & Lung tissue & + \\
\hline 2 & 7 & Female & +++ & Typical CBPP lesions & Lung tissue & + \\
\hline 1 & 6 & Female & ++ & No CBPP lesions & Lung tissue & + \\
\hline
\end{tabular}

\section{DISCUSSION}

The overall animal level seroprevalence of CBPP was $(14.6 \%, 95 \%$ CI: $11.80-17.73)$ which is comparably in agreement with the findings of various researchers who reported prevalence of $12 \%$ in southern zone of Tigray region of Ethiopia (20), 14\% in Niger state of north central Nigeria (33), $14.3 \%$ in Kajiado district of Kenya (34), 17.19\% in Khartoum state of Sudan (35), and 17\% in Turkana district of Kenya (36). On the other hand, the finding of this study was higher than the results of Gizaw (11) in Somali regional state (10.3\%), Ahmed (37) in Borena (9.4\%), Atnafie et al. (22) in Bishoftu abattoir and Adama quarantine (6.85\%), Alemayehu et al. (19) in Borena pastoral of Oromia (0.4\%), Kassaye and Molla (18) in export quarantine of in and around Adama (4\%), Geresu et al. (24) in Dello Mena and Sawena districts of Bale zone (6.51\%), Schnier et al. (38) in south western Kenya (9.7\%), Mbengue et al. (39) in Senegal (0.43\%), Mtui-Malamsha (40) in the Maasai ecosystem of south-western Kenya (11.21\%) and Zarina et al. (41) in north east states of Peninsular Malaysia Pertanika (8\%). On the contrary, it was by far much lower than the previous reports of Ebisa et al. (21) with $31.8 \%$ in Amaro district of southern people nations and nationalities people (SNNP) region, Mersha (23) with $28.5 \%$ in selected districts of western Oromia, Soromou et al. (42) with $21.05 \%$ in Guinea and Suleiman et al. (43) with 30.2\% in agro-pastoral areas of Nigeria.

The overall herd level seroprevalence of CBPP was (54\%, 95\% CI: 44.35-63.40). This overall herd level seroprevalence is closely in agreement with the finding of Suleiman et al. (43) with $54.7 \%$ in agro-pastoral areas of Nigeria. However, higher than the previous report of Bonnet et al. (44) with $4.6 \%$ in the Ethiopian highlands, Gizaw (11) with $30.4 \%$ in Somali regional state of Ethiopia, Zarina et al. (41) with $17 \%$ in north east states of Peninsular Malaysia Pertanika and Alhaji and Babalobi (33) with $47.2 \%$ in Niger state of north central Nigeria. On the other hand, the finding was lower than the report of Mtui-Malamsha (40) with $85 \%$ in the Maasai ecosystem of south-western Kenya.

The rates of CBPP infection reported to vary from one region to another even within the region $(2,3)$. CBPP occurrence is described to cover large area of the country. Different seroprevalences of CBPP were recorded across the study districts and peasant associations such as animal level seroprevalence was $(20.1 \%$, 95\% CI: $15.66-25.24)$ in Ilu Gelan district while (9\%, 95\% CI: 5.98-12.95) in Sibu Sire $(p<0.05)$. Similarly, significantly higher prevalence was observed in Ale Wara Ilu $(22.1 \%)$ PA than Cheri Jarso (7\%) PA. The present result of variation seroprevalence within closely related study locations (districts and PAs) was in agreement with the finding of different authors such as Ebisa $e t$ al. (21) in Amaro district of SNNP region, Mersha (23) in selected districts of western Oromia, Teklue et al. (20) in Southern zone of Tigray region, Gizaw (11) in Somali regional state, Maritim (36) in Turkana district of Kenya. This might indicate the presence of CBPP infection depends on certain associated risk factors like the epidemiology of the disease, agroecology, livestock population and movement, and different management system may be applied across the study sites such as the presence or absence of communal grazing and watering areas within locations and the probability of introduction new purchased animal from disease endemic area (3). Therefore, the probabilities of animals to be infected with CBPP disease as well as with other diseases are various across locations even it is different within similar agro-ecological locations.

There was no significant difference of CBPP seroprevalence among the sex which was $(16.4 \%, 95 \%$ CI: $12.03-21.58)$ in male and $(13.2 \%, 95 \%$ CI: 9.71-17.35) in female animal. This finding is in agreement with the work done by Ebisa et al. (21) in Amaro district of SNNP region, Mersha (23) in selected districts of western Oromia, Teklue et al. (20) in Southern zone of Tigray region of Ethiopia, 
Suleiman et al. (38) in agro-pastoral areas of Nigeria, and Alhaji and Babalobi (33) in Niger state of north central Nigeria. Therefore, the study result agreed with Provost et al. (45) who reported sex has not been considered as the risk factors that affecting the susceptibility of cattle to CBPP disease infection. On the other hand, contradicted with the finding of Schnier (38) in south western Kenya and Mtui-Malamsha (40) in the Maasai ecosystem of south western Kenya who reported statically significant difference among sex.

Age is supposed to have some association with occurrence of CBPP disease because young or calves become more resistant to experimental infection than adult cows $(45,46)$. The result of this study also revealed there was statistically significant difference of CBPP disease among the age groups. Higher seroprevalence was recorded in adult animals (18.1\%, 95\% CI: 14.14-22.63) than in young animals (9.6\%, 95\% CI: $6.2-14.1)$. The likelihood of seropositivity of adult cattle (OR $=2.1,95 \%$ CI: 1.24 $3.46, p=0.005)$ was two times more seropositive to CBPP than young cattle. This result is in consistent with the reports of Elhassan (35) in Khartoum state of Sudan, Alhaji and Babalobi (33) in Niger state of north central Nigeria, Mtui-Malamsha (35) in the Maasai ecosystem of south western Kenya and Schnier et al. (38) in south western Kenya. In contrast, there are different studies that reported insignificant associations such as Ebisa et al. (21) in Amaro district of SNNP region, Teklue et al. (20) in southern zone of Tigray region, Mersha (23) in selected districts of western Oromia and Suleiman et al. (43) in agro-pastoral areas of Nigeria. Calves were reported to be relatively more resistant to infection by $\mathrm{Mmm}$ than adult cattle $(47,48)$, which may be explained by the fact that increasing age is a surrogate measure of repeated exposure (49) and similar findings were reported from Sudan by Zessin et al. (50) and McDermott et al. (51). Moreover, the study also agreed with Thomson (4) who reported that factor like extremes of age may predispose to tissue invasion of CBPP disease.

Seroprevalence of CBPP was highest in cattle with poor body condition $(23.3 \%$, 95\% CI: $15.93-$ $32.03)$ as compared to cattle with medium body condition (14.2\%, 95\% CI: 10.76-18.35) and good body condition $(6.4 \%, 95 \%$ CI: $2.62-12.78)$. This finding is in agreement with the report of Ebisa $e t$ al. (21), Suleiman et al. (43) and Mtui-Malamsha (35). The poor body conditioned cattle were ( $\mathrm{OR}=4.4,95 \%$ CI: $1.84-10.64, p=0.001)$ four times more likely to have the CBPP compared to the good body conditioned cattle. This could due to related to the weak protective immune response in poor body conditioned cattle compared to good ones. Loss of body condition is one of the indications for the presence of the infection in the animal. Mostly CBPP chronic carrier animals became emaciated because of the clinical characteristics of the disease. Besides, animals with good body condition have relatively good immunological response to the infectious agent than animals with medium and poor body condition score (3). It was supposed that CBPP seropositive animals had poor body conditions than seronegative animals; thus, the present study result confirmed the assumption. This indirectly describes the impact of the disease associated with loss of productivity of cattle.

There was statistically significant between history of previous respiratory disorder/health problems and seroprevalence of CBPP disease $(p=0.004)$. The prevalence was highest in respiratory disordered animals $(18.8 \%$, 95\% CI: 14.52-23.80) compared to cattle that had not experienced respiratory problems $(10.2 \%$, 95\% CI: 6.95-14.34). Respiratory disordered animals $(\mathrm{OR}=2.04,95 \%$ CI: $1.26-$ 3.31) were two times more seropositive of CBPP disease as compared to healthy animals which in line with the report of William and Amanfu (52) and Mtui-Malamsha (40). Among the clinical signs of CBPP respiratory disorders like laboured painful breathing, coughing and as severity of the disease progress lung lesions will be observed. CBPP is typically characterised by fibrinous pneumonia, serofibrinous pleuritis, and oedema of the interlobular septa of the lungs, frequently the symptoms of CBPP disease is associated with lung organs $(53,54)$. In this study the reason of higher seroprevalence in cattle with history of respiratory disordered animal was due to the clinical characteristics of the disease. Hence, based on the present study result, if animals were exhibited any respiratory health problem in the study area; it could be an indication of CBPP infection.

The prevalence was highest in cattle with large herd size $(30.6 \%, 95 \%$ CI: 23.3-38.74) as compared to cattle with small herd size cattle $(5.5 \%, 95 \%$ CI: $2.74-9.01)$. The large herd size groups $(\mathrm{OR}=7.6$, 95\% CI: 3.84-14.94, $p=0.000$ ) were seven times more likely to have the CBPP infection compare to the small herd size cattle groups. The finding is in line with the report of Alemayehu et al. (19) in Borena pastoral area of Southern Ethiopia, Suleiman et al. (43) in agro-pastoral areas of Nigeria who 
reported large herd size cattle groups significantly associated with CBPP seroprevalence. Compact grouping of herds during grazing or herding and confinement at night within small enclosures or kraal such conditions are eminently favourable for infection of CBPP disease (45). Herds which had many animals were more likely to be CBPP positive compared to herds with few animals. The rate of effective contact between CBPP-infected and susceptible cattle is reported to be higher in larger herds (47), reason for which could be explained as the contagious nature of CBPP and its direct mode of transmission which might be increased by crowding and increased frequency of contacts as herd size increases. Furthermore, Majekodunmi et al. (55) reported that CBPP prevalence may even be higher in parts of predominated by pastoral systems such as nomadic and transhumant where frequently larger herds are kept.

There is not any report on the issue of stage of parity susceptibility to CBPP disease so far. In this study, the seroprevalence was found to be higher in Pluriparus caws $(17.1 \%, 95 \%$ CI: $11.30-24.42)$ as compared to with single parity $(16.7 \%, 95 \%$ CI: 7.48-30.22) and heifers (7.6\%, 95\% CI: $3.69-13.49)$. As the current result showed the likelihood of seropositivity of CBPP was increased with increased cattle parity such as the likelihood of seropositivity with CBPP disease of multiple parity $(\mathrm{OR}=2.5$; 95\% CI: $1.16-5.51, p=0.020$ ) was 2.5 times more than heifer as well as the likelihood of seropositivity with CBPP disease of single parity cows (OR $=2.4,95 \%$ CI: $0.9-6.61, p=0.079$ ) were 2.4 times more than heifers. The reason of higher prevalence in Pluriparous could be associated with age of animal because those multiple parity animals were older than single parity and heifers. According to the report of Provost et al. (45), Titus (46) and Lesnoff et al. (47), heifers respond weakly to vaccination but become more resistant to experimental infection than adult cows.

Detection of $\mathrm{Mmm}$ was made directly from lung tissue that sampled from seropositive animals with the application PCR assay using the primers that specific to Mmm. Of the four animal lung tissues sampled, only in two samples (50\%) lesions of CBPP observed while the other two lung samples were negative upon post-mortem examination; however, with PCR amplifications of the genomic DNA results, Mmm was detected in all four samples $(100 \%)$. The positive CBPP pathology was taken as a definite mark of $\mathrm{Mmm}$ infection in the lungs of the animals. The absence of gross pathology was observed in positive both serological (cELISA) and molecular (PCR) tests which in line with the result of Bashiruddin et al. (56). However, according to the report of Bashiruddin et al. (56) the lack of appropriate gross pathology in the presence of positive serological or other detection tests like PCR may not be usual. The reason of absence of lesions on the two animals during post-mortem examination could be the animals were treated with antibiotics, because antibiotic treatment is definitively stopped the extension of lesions as the report of Thiaucourt et al. (57). In addition, Alhaji and Babalobi (58) also reported that culturing and post-mortem diagnosis of CBPP has not always have been successful in epidemiological surveillance especially where animals have been treated with antibiotics which is a common practice by animal health professionals. One of the unique advantage of PCR is the ability to detect died antigens, thus, the other probability of absence of lesion on the two samples could be due to died antigen, because died antigen is unable to induce lesions while capable to induce antibody production. According to the report of Bashiruddin et al. (56) detection systems that do not rely on the viability of $\mathrm{Mmm}$ should be considered favourably. Collectively, PCR was the most successful detection method from tissues samples $(56,59)$. Besides, this finding further validates the application of cELISA test for diagnosis of CBPP during epidemiological study of the disease, particularly in case of advance confirmatory diagnostic like culturing; biochemical test, molecular test and post-mortem examination were not accessible.

\section{CONCLUSIONS AND RECOMMENDATIONS}

The output of this study has indicated that contagious bovine pleuropneumonia was endemic in the study area and confirmed by serology and PCR. Out of 576 sampled animals 84 were seropositive and an overall $14.6 \%$ seroprevalence was recorded using cELISA test and of which, $9 \%$ recorded from Sibu Sire while $20.1 \%$ from Ilu Galan district. The potential risk factors like location (district), age, history of respiratory health problem, body condition score and herd sizes were statistically significant effect on seroprevalence of the CBPP disease. Similarly, significantly higher prevalence was observed in multiple parity cows than heifers and in Ale Wara Ilu (22.1\%) PA than Cheri Jarso (7\%) PA. This indicates the presence of CBPP infection depends on herd management system or animal husbandry, and host related potential risk factors. Of the four seropositive animals that tested with PCR Mmm was 
detected in all sampled animals and the existence of the disease has been confirmed in the present study. Therefore, based on the above conclusion the following recommendations were forwarded:

- Further investigation in wide geographical areas and large sample size using reliable tools like molecular technique and biochemical test are needed in order to know the exact epidemiological scenario of the disease.

- The farmers should be made aware of about CBPP disease particularly the economic importance, transmissions methods, and controlling techniques of the disease through veterinary extension education and possible means like media.

- The government has to apply controlling and prevention strategy of this economically devastating disease of cattle through carry out careful herd management and control of animal movement within community and implementing regular vaccination of animals.

\section{ACKNOWLEDGEMENTS}

My special thanks also go to Oromia Agricultural Research Institute (OARI) and also heartedly acknowledged Bako Agricultural Research Centre (BARC) for affording me the necessary materials to do the work. I am also highly indebted to all staff members of the centre especially Mr Mamo Mokonen, Mr Yohanis Kejela, Mr Badasa Bodena, and Gash Tade (driver) who shared many challenges with me during field data collection. As well as I would like to extend my thanks to National Veterinary Institute (NVI) for their involuntary to showed me the laboratory technical works, particularly Mr Alebachewu Belay who dedicatedly thought me the technical work of PCR laboratory part.

\section{REFERENCES}

[1] Food and Agriculture Organization of the United Nations (FAO) (2004). - Animal production and health Proceedings. FAO, 00100 Rome, Italy. Available at: http://www.fao.org/3/a-y5019e.pdf (accessed on 26 May, 2020)

[2] World Organisation for Animal Health (OIE) (2018). - Contagious bovine pleuropneumonia (infection with Mycoplasma mycoides subsp. mycoides). In Manual of Diagnostic Tests and Vaccines for Terrestrial Animals. Chapter 3.4.8. OIE, Paris, France, 1097-1112. Available at: www.oie.int/fileadmin/Home/eng/ Health_standards/tahm/3.04.08_CBPP.pdf (accessed on 6 March 2020).

[3] Radostits O.M., Gay C.C., Hinchcliff K.W. \& Constable P.D. (2007). - A Textbook of the Diseases of Cattle, Sheep, Goats, Pigs and Horses of Veterinary Medicine: 10th Ed., Saunders Elsevier, Madrid, Spain, $1131-1135$.

[4] Thomson, G. R. (2005). Contagious bovine pleuropneumonia and poverty: A strategy for addressing the effects of the disease in sub-Saharan Africa. Research report, DFID Animal Health Programme, Centre for Tropical Veterinary Medicine, University of Edinburgh, UK. (Which was based on Dr. Jeff Mariner's work, initially reported as the dynamics of CBPP endemism and the development of effective control/eradication strategies for pastoral communities (Mariner, 2003)

[5] Tambi N.E., Maina W.O. \& Ndi C. (2006). - An estimation of the economic impact of contagious bovine pleuropneumonia in Africa. Rev. Sci. Tech. Off. Int. Epiz., 25 (3), 999-1012. doi:10.20506/rst.25.3. 1710.

[6] Food and Agriculture Organization of the United Nations (FAO) (2002). - FAO Recognizing contagious bovine pleuropneumonia. FAO Animal Manual Health Manual, FAO, Rome, 13: 3-17. Available at: http://www.fao.org/3/a-y4142e.pdf (accessed on 26 May, 2020)

[7] Amanfu W. (2009). - Contagious bovine pleuropneumonia (lung sickness in Africa), Onderstepoort J. Vet. Res., 76: 13-17. doi:10.4102/ojvr.v76i1.55.

[8] Marobela-Raborokgwe C. (2011). - Contagious bovine pleuropneumonia in Botswana: experience with control, eradication, prevention and surveillance. Vet. Ital.; 47: 397-405.

[9] World Organization for Animal Health (OIE) (2001). - Diagnostic tests for contagious bovine pleuropneumonia (CBPP). Report of the scientific Committee on Animal Health and Animal Welfare. OIE, Paris, Pp: 2-8. Available at: https://ec.europa.eu/food/sites/food/files/safety/docs/sci-com_scah_ out63_en.pdf (accessed_on 27 may 2020)

[10] Wade A., Yaya, A., El-Yuguda A. D., and Unger H., Nafarnda (2015). - The prevalence of contagious bovine pleuropneumonia in cameroon: A case study Garoua Central Abattoir, Cameroun. J. Vet. Med. Res., 2: 10-29.

[11] Gizaw G. M. (2004). - Serological, clinical and participatory epidemiological survey of contagious bovine pleuropneumonia in Somali region, Ethiopia. Thesis for the Degree of Master of Science, Addis Ababa 
Epidemiological Study and Causative Agent Identification of Contagious Bovine Pleuropneumonia in Selected Districts of Western Ethiopia

University, Faculty of Veterinary Medicine, Debre Zeit, Ethiopia, $91 \mathrm{pp}$. Available at: https://pdfs.semanticscholar.org/37e0/_9efaeb94a57313426d43bffac3344a9d1f35.pdf (accessed on 6 March 2020).

[12] Tambi E. N. and Maina O. W. (2006). - Ex-ante economic analysis of animal disease surveillance, published in OIE Review. doi: 10.20506/rst.23.3.1517.

[13] Ministry of agriculture (MOA) (2003). - Monthly animal health status report; ministry of agriculture veterinary services, epidemiology unit, Addis Ababa, Ethiopia

[14] Admassu B., Shite A. and Molla W. (2015).-Contagious bovine pleuropneumonia in Ethiopia (Review Article), Acad. J. Animal Dis., 4: 87-103.

[15] World Organization for Animal Health (OIE) (2008). - Manual of Diagnostic Tests and Vaccines for Terrestrial Animals (Mammals, birds and bees), 6th ed. Office the International Des Epizooties, Paris. Pp: 712-724. Available at: https://www.oie.int/doc/ged/D7709.PDF (accessed on 10 June 2020)

[16] Hubschle O., K. and Nicholas R. J. (2004). - Danofloxacin treatment of cattle affected by CBPP. Vet. Rec., 155: 404.

[17] Center of Food security and public health (CFSPH) (2015). - Contagious bovine pleuropneumonia institute for international cooperation in animal biotechnology. Last updated: November, 2015, Pp: 1-5

[18] Kassaye D., and Molla W. (2013). - Seroprevalence of contagious bovine pleuropneumonia at export quarantine centers in and around Adama, Ethiopia. Trop. Anim. Health Prod., 45: 275-9. doi:10.1007/ s11250-012-0212-3.

[19] Alemayehu G., Leta S., and Hailu B. (2015). - Seroprevalence of contagious bovine pleuropneumonia in bulls originated from Borena pastoral area of Southern Ethiopia, Trop. Anim. Health Prod., 47: 983-7. doi:10.1007/s11250-015-0820-9.

[20] Teklue T., Tesfay T., Nirayo T., Hailu B., Wayu S., Atsbha T. (2015). - Epidemiological Status of Contagious Bovine Pleuropneumonia in Southern Zone of Tigray Regions, Northern Ethiopia. Journals/Biology and Life Sciences/Animal and Veterinary Sciences, 3:32-36. doi:10.11648/ j.avs.201 50301.17.

[21] Ebisa T., Hirpa, E. and Aklilu F. (2015). - Study on seroprevalence and risk factors of Contagious Bovine Pleuropneumonia in Southern nation in southern Nation and Nationality and People of Ethiopia Regional State in Amaro special district Science, Technology and Arts Research Journal, 4: 106-112. doi:10.4314/star.v4i4.15.

[22] Atnafie B., Goba H., Sorri H. and Kasaye S. (2015). - Sero-prevalence of contagious bovine pleuropneumonia in abattoirs at Bishoftu and export oriented feedlots around Adama, department of agriculture, Addis Ababa University, P.O. Box: 34, Fiche, Ethiopia. Global Veterinaria., 15: 321-324.

[23] Mersha T. (2016). - Sero-prevalence of contagious bovine pleuropneumonia and its potential risk factors in selected sites of Western Oromia, Ethiopia. Ethio. Vet. J., 20: 31-41.

[24] Geresu M.A., Kedir K., Birhanu D. and Teshome A. (2017). - Sero-epidemiological investigation and risk factors for contagious bovine pleuropneumonia infection of cattle in Dello Mena and Sawena Districts of Bale Zone, South Eastern. Ethiopia Journal of Public Health and Epidemiology, 9: 122-132. doi:10.5897/JPHE2016.0853.

[25] Rege J. O. (1999). - The state of African cattle genetic resources I. Classification framework and identification of threatened and extinct breeds. Animal Genetic Resources Information Bulletin No. 25,125. doi:10.1017/S1014233900003448.

[26] Domestic Animals Genetic Resources Information System (DAGRIS) (2007). - International Livestock Research Institute. Addis Ababa. Ethiopia. http://dagrisilri.Cgiar.org.

[27] Tola, D. B. (2015). - On Farm Phenotypic Characterization of Indigenous Cattle and their Production Systems in Bako Tibe and Gobu Sayo Districts of Oromia Region, Ethiopia, MSc Thesis. Haramaya University, Ethiopia.

[28] Thrusfield M.V. (2007). - Veterinary epidemiology. 3rd Ed. Published by Black Well science Ltd. Edinburgh, UK. Pp. 229-250. Available at: https://books.google.com.et/books?id= JPRqOU_fgWUC\&printsec $=$ frontcover\&source=gbs_ge_summary_r\&cad $=0 \# \mathrm{v}=$ onepage \&q\&f=false (accessed on 10 June 2020)

[29] Tadeg W. M., Gudeta F. R., Mokenon T. Y., Asfaw Y. T., Biru A. L. and Reda A. A. (2015). - Seroprevalence of Small Ruminant Brucellosis, and its effect on reproduction at Tellalak district of Afar region. J. Vet. Med. Animal health. 7:111-116. doi:10.5897/JVMAH2014.0287.

[30] Gebremedhin E.Z., Agonafir A., Tessema T.S., Tilahun G., Medhin G., Vitale M., Di Marco V., Cox E., Vercruysse J., Dorny P. (2013). - Sero-epidemiological study of ovine toxoplasmosis in East and West Shewa Zones of Oromia Regional State, Central Ethiopia. BMC Vet. Res., 9: 117. doi:10.1186/1746-61489-117. 
[31] Nicholson, M J and Butterworth, M H. (1986): A guide to condition scoring of zebu cattle. International Livestock Centre for Africa, Addis Ababa, Pp: 1-5. Available at: https://pdfs.semanticscholar. org/b3f1/3681e798f3ab4d8ae01b0ea1c92ba968f01f.pdf (accessed on 27 July 2020)

[32] Johansson, K. E., Persson, A. and Persson, M. (1998): Diagnosis of contagious caprine and contagious bovine pleuropneumonia by PCR and restriction enzyme analysis. In: towards livestock disease diagnosis and control in the 21st century, IAEA-SM-348/12. International Atomic Energy Agency, Pp. 137-158. Available at: https://inis.iaea.org/search/search.aspx?orig_q=RN:29065543 (accessed on 24 July 2020)

[33] Alhaji N. B. and Babalobi O. O. (2016). - Sero-positivity and associated risk factors for contagious bovine pleuropneumonia under two cattle production systems in North Central Nigeria. Trop Anim Health Prod., 48: 311-320. doi:10.1007/s11250-015-0952-y.

[34] Matua-Alumira R. W., Nganga Z., Kiara H., Matere C., Mbithi F., Mwirigi M., Marobella-Raborogwe C. and Sidiadie S. (2006). - The prevalence of contagious bovine pleuropneumonia (CBPP) in cattle under different production systems in Kajiado district, Kenya. Proceedings of the 11th Symposium on Veterinary Epidemiology and Economics 6-8th June 2006 Cairns, Canada. Available at: www.sciquest.org.nz (accessed on 24 2020)

[35] Elhassan I. H. (2012). - Prevalence and risk factors associated with contagious bovine pleuropneumonia it in Khartoum State, MSc Thesis University of Khartoum College of Veterinary Medicine, Sudan. Pp: 5367. Available at: http://repository.sustech.edu/handle/123456789/7728 (accessed on 24 2020)

[36] Maritim W. K. (2009). - The seroprevalence and risk factors of contagious bovine pleuropneumonia in the Northwestern area of Turkana District, Kenya. MSc thesis desertion, College of Agriculture and Veterinary Sciences (CAVS). Available at: http://erepository.uonbi.ac.ke/handle/11295/18835 (accessed on 24 July 2020)

[37] Ahmed I. (2004). - Epidemiological study of contagious bovine pleuropneumonia in Borana pastoral areas using complement fixation test and competitive enzyme-linked immunosorbent assay. Thesis for degree of Master of Veterinary Epidemiology, Faculty of Veterinary Medicine, University of Addis Ababa, Ethiopia. Pp: 41-60.

[38] Schnier C., Mtui-Malamsha N. J., Cleavel S., Kiara H., Grace D., McKeever D. J. and Zadoks R. N. (2006). - CBPP Seroprevalence and associated risk factors in the Maasai ecosystem of South-western Kenya. International Livestock Research Institute, Nairobi, Kenya. Available at: http://www. sciquest. org.nz/node/67956 (accessed on 24 July 2020)

[39] Mbengue MB. J. Sarr, Fall Massal. Sero - epidemiological studies on contagious bovine pleuropneumonia (CBPP) in Senegal. American Journal of Research Communication, 2013, 1(3): 190-199\} www.usajournals.com, ISSN: 2325-4076. Available at: https://era.ed.ac.uk/handle/1842/4379 (accessed on 24 July 2020)

[40] Mtui-Malamsha N. J. (2009). - Contagious Bovine Pleuropneumonia (CBPP) in the Maasai ecosystem of south-western Kenya: Evaluation of seroprevalence, risk factors and vaccine safety and efficacy. J. Gen. Microbiol. 14: 97-207. Available at: http://hdl.handle.net/1842/4379 (accessed on 24 July 2020)

[41] 41. Zarina M., Zamri-Saad M., Latiffah H., Shahrom M. S. and Norlida O. (2016). - Seroprevalence and detection of contagious bovine pleuropneumonia (CBPP) in Northeast States of Peninsular Malaysia Pertanika. J. Trop. Agric. Sci., 39: 257 - 265. Available at: https://www.semanticscholar.org/ paper/Seroprevalence-and-detection-of-contagious-bovine-ZarinaSaad/ceb00efb36d6c9071efb6d3f8aa5dfe07fa9d613 (accessed on 24 July 2020)

[42] Soromou L. W., Dabo., Cissé M., Sidimé Y., Keyra M., Sylla M. K., Baldé A., Haba P. F. and Kéita F. (2014). - Seroprevalence of contagious bovine pleuropneumonia in the prefecture of Dabola, Upper Guinea. Africa Journal of Animal and Biomedical Sciences 8: 1819-4214

[43] Suleiman A., Bello M., Dzikwi A., Talba A. M., Grema H. A., Yaqub A. and Geidam Y. A. (2015). Serological prevalence of contagious bovine pleuropneumonia in agro-pastoral areas of Nigeria. Trop Anim Health Prod., 47: 1033-1042. doi:10.1007/s11250-015-0824-5.

[44] Bonnet P., Lesnoff M., Thiaucourt F., Workalemahu A. and Kifle D. (2005). - Seroprevalence of contagious bovine pleuropneumonia in Ethiopia highlands (West Wollega zone, Bodji District). Ethiop. Vet. J., 9: 85-93. Avalable at : https://hdl.handle.net/10568/28531 (accessed on 24 July 2020)

[45] Provost A., Perreau P., Bréard A., Le Goff C., Martel J.L. \& Cottew G.S. (1987). - Contagious bovine pleuropneumonia. In Mycoplasmoses of ruminants. Rev. Sci. Tech. Off. Int. Epiz., 6 (3), 625-679. doi:10.20506/rst.6.3.306.

[46] Titus K.D. (2003). - A participatory epidemiologic study of contagious bovine pleuropneumonia in Lapur Division, Turkana District, Kenya. MVEE thesis, University of Nairobi. 113 pages. Available at: http://erepository.uonbi.ac.ke:8080/xmlui/handle/123456789/24330 (accessed on 24 July 2020)

[47] Lesnoff M., Laval G., Bonnet P., Chalvet-Monfray K., Lancelot R. and Thiaucourt F. (2004). - A mathematical model of the effects of chronic carriers on the within-herd spread of contagious bovine 
Epidemiological Study and Causative Agent Identification of Contagious Bovine Pleuropneumonia in Selected Districts of Western Ethiopia

pleuropneumonia in an African mixed crop-livestock system. Prev.Vet. Med., 62: 101-170. doi:10.1016/j.prevetmed.2003.11.009.

[48] Schnier C, McKeever D. J., Mtui-Malamsha N. J., Cleavel S., Kiara H. and Grace D. (2009). - CBPP seroprevalence and associated risk factors in the Maasai ecosystem of southwestern Kenya.International Symposia on Veterinary Epidemiology and Economics proceedings, ISVEE 12: Proceedings of the 12th Symposium of the International Society for Veterinary Epidemiology and Economics, Durban, South Africa, Theme 2 - Investigation of determinants and distribution of disease: Determinants, Disease distribution \& determinants. Available at: http://www.sciquest.org.nz/node/67956 (accessed on 24 July 2020)

[49] Boelaert F., Speybroeck N., de Kruif A., Aerts M., Burzykowski T., Molenberghs G. and Berkvens D. L. (2005). - Risk factors for herpesvirus-1 seropositivity. Prev.Vet. Med., 69: 285-295. doi:10.1016/j. prevetmed.2005.02.010.

[50] Zessin K. H., Baumann M., Schwabe C. W. and Thornburn M. (1985). - Analysis of baseline surveillance data on contagious bovine pleuropneumonia in the southern Sudan. Prev.Vet. Med., 4: 371-389. doi:10.1016/0167-5877(85)90014-5.

[51] McDermott J., Deng K. A., Janatileka T. N. and Jack. M. A. (1987). - A cross sectional cattle disease study in Kongor rural council, southern Sudan. Prevalence estimates age, sex and breed associations for brucellosis and contagious bovine pleuropneumonia. Prev.Vet. Med., 5: 111-123. doi:10.1016/01675877(87)90016-X.

[52] William A. G. and William Amanfu W. (2002). - Preparation of Contagious Bovine Pleuropneumonia Contingency Plans, Food and Agriculture Organization of the United Nations, Rome, 2002. FAO Animal Health Manual No. 14. Available at: http://www.fao.org/publications/card/en/c/1637789f-c95c-5e77-bf21c9f3a32c9930/ (accessed on 24 July 2020)

[53] EMPRES (2002). - Recognizing contagious bovine pleuropneumonia (REVISED EDITION). FAO Animal Health Manual, FAO, Rome. No. 13 (Rev. 1). Available at: http://www.fao.org/publications/ card/en/c/f88b9d40-f068-5fdc-85f3-03b40044f33f/ (accessed on 24 July 2020)

[54] Hamsten C. (2009). - Protein based approaches to understand and prevent contagious bovine pleuropneumonia. School of Biotechnology, Royal Institute of Technology (KTH), Stockholm, Sweden. Available at: https://www.diva-portal.org/smash/get/diva2:235819/FULLTEXT02.pdf (accessed on 24 July 2020)

[55] Majekodunmi A.O., Fajinmi A., Dongkum C., Shaw A.P.M., and Welburn S.C. (2014). - Pastoral livelihoods of the Fulani on the Jos Plateau of Nigeria. Pastoralism, 4, doi:10.1186/s13570-014-0020-7.

[56] Bashiruddin J.B., Santis P., Persson A., Ball H., Regalla J. (2005). - Detection of Mycoplasma mycoides subspecies mycoides SC in bovine lung and lymph node tissues by culture, sandwich ELISA and polymerase chain reaction systems. Research in Veterinary Science, 78:199-205. doi:10.1016/ j.rvsc.2004.09.004.

[57] Thiaucourt F., Van der Lugt J.J. \& Provost A. (2004). - Contagious bovine pleuropneumonia. In Infectious diseases of livestock, 2nd Ed (J.A.W. Coetzer \& R.C. Tustin, eds), Volume 3. Oxford University Press, Cape Town, 2045-2059.

[58] Alhaji N. B. and Babalobi O. O. (2015). - Molecular epidemiology of contagious bovine pleuropneumonia by detection, identification and differentiation of Mycoplasma mycoides subsp. mycoides in Niger State, Nigeria, Sokoto J. Vet. Sci., 13: 1-8. doi:10.4314/sokjvs.v13i3.1.

[59] Bashiruddin J.B., Santini F.G., De Santis P., Visaggio M.C., Di Francesco G., Dangelo, A., Nicholas R.A.J. (1999). - Detection of Mycoplasma mycoides subspecies mycoides in tissues from an outbreak of contagious bovine pleuropneumonia by culture, immunohistochemistry and polymerase chain reaction. Vet. Rec., 145: 271-274. doi:10.1136/vr.145.10.271.

Citation: Tesfaye Mersha Cherinnat, "Screening of Eggplant Epidemiological Study and Causative Agent Identification of Contagious Bovine Pleuropneumonia in Selected Districts of Western Ethiopia”. International Journal of Research Studies in Biosciences. 2020; 8(8): 1-16. DOI: https://doi.org/10.20431/2349. 0365.0808001 .

Copyright: (C) 2020 Authors. This is an open-access article distributed under the terms of the Creative Commons Attribution License, which permits unrestricted use, distribution, and reproduction in any medium, provided the original author and source are credited. 